\title{
A Survey of the Cardiology Care Delivered to Cancer Patients in Nigeria
}

\author{
Alikor Chizindu Akubudike ${ }^{1, \text { *, Weje Chituru Chioma }}{ }^{2}$ \\ ${ }^{1}$ Department of Medicine, Faculty of Clinical Sciences, College of Health Sciences, University of Port Harcourt, Port Harcourt, Nigeria \\ ${ }^{2}$ Department of Medicine, University of Port Harcourt Teaching Hospital, Port Harcourt, Nigeria
}

Email address:

alikorchizindu@yahoo.com (A. C. Akubudike),wejechituru@gmail.com (W. C. Chioma)

${ }^{*}$ Corresponding author

\section{To cite this article:}

Alikor Chizindu Akubudike, Weje Chituru Chioma. A Survey of the Cardiology Care Delivered to Cancer Patients in Nigeria. Cancer Research Journal. Vol. 8, No. 1, 2020, pp. 8-12. doi: 10.11648/j.crj.20200801.12

Received: November 21, 2019; Accepted: December 9, 2019; Published: January 17, 2020

\begin{abstract}
BACKGROUND: The incidence of cardiovascular disease is on the rise and this is no less so amongst the population of individuals who are affected by cancer as improvement over the years in cancer treatment options have brought about improved outcomes in terms of overall patient survival and outcomes but has additionally also illuminated the side effects of these cancer treatment as patients live longer to manifest them thereby increasing morbidity and mortality. In Nigeria, there is paucity of data on cardio-oncology and this study will be the first documented study assessing the level of knowledge and the activity of cardiology care provided to oncology patients who develop cardiovascular disease in Nigeria and will therefore serve as a template towards the development of cardio-oncology services in Nigeria. METHODS: The survey was questionnaire-based involving cardiologist in Nigeria. They first part assessed the demographic characteristics of participants. The second part of the questionnaire assessed participants' self-admitted expertise in the management of cardiovascular conditions complicating cancer treatment. RESULTS: There were more male $(57.14 \%)$ than female $(42.86 \%)$ respondents. More than two-thirds of respondents $(71.4 \%, n=55)$ were aged 30-44 year. Cumulatively, the South-south and South-western regions accounted for over two-thirds of responses $(72.43 \%, \mathrm{n}=55)$. Over three-thirds of respondents $(83.12 \%, \mathrm{n}=)$ worked at teaching hospitals. Majority $(89.5 \%, \mathrm{n}=68)$ of ambulatory cancer patients in need of cardiology care received this service in a general cardiology clinic with only $10.5 \%(\mathrm{n}=8)$ receiving care at a cardio-oncology centre. Majority of respondents $(67.1 \%$, $\mathrm{n}=51$ ) dId not receive referrals from general practitioners or other specialists to evaluate cardiac problems in patients who had received cancer treatment. $80.5 \%$ of participants $(\mathrm{n}=62)$ said that they either did not know about the ESC position paper or knew about it but did not apply its suggestions to their practice. CONCLUSION: Most cancer patients requiring cardiovascular care are seen in the general cardiology clinic of Government owned hospitals in Nigeria. Although the knowledge of cardiologists in the management of cardiovascular complications of cancer patients is adequate, referral from General Practitioners is low. The ESC position paper on cardio-oncology is poorly known and utilized by cardiologist in the care of cancer patients with cardiovascular complications with the field of cardio-oncology generally regarded as a new topic in cardiology requiring more information on its dissemination and acceptance. This survey therefore makes obvious the dearth of knowledge regarding cardio-oncology that is prevalent in Nigeria. It is hoped that this will ignite a change in this aspect. There is therefore an urgent need to for all stakeholders to join force together towards the development of cardio-oncology skills and services in Nigeria.
\end{abstract}

Keywords: Cardiology Care, Delivered, Cancer Patients, Nigeria

\section{Introduction}

The incidence of cardiovascular disease is on the rise and this is no less so amongst the population of individuals who are affected by cancer as improvement over the years in cancer treatment options have brought about improved outcomes in terms of overall patient survival and outcomes but has additionally also illuminated the side effects of these cancer treatment as patients live longer to manifest them 
thereby increasing morbidity and mortality [1-2]. Of these side effects, cardiovascular diseases (CVDs) are documented to be prominent among cancer survivors with its consequent negative impact on morbidity and mortality [3]. The toxic effects of these treatment options on the heart structure and function is the implicated mechanism for these cardiovascular diseases among other mechanism [4].

Monitoring cardiac function before, during, and after treatment helps doctors to detect early cardiac damage, enabling regimen modifications as cardiovascular disease can affect individuals at different points in the continuum of their cancer care. It can predate the cancer and be worsened by the cancer therapy, occur for the first time whilst cancer treatment is ongoing, or be discovered following cancer treatment [5-9]. Monitoring tools useful in this evaluation will include echocardiography, cardiac troponins and brain natriuretic peptide (BNP) which can detect pre-symptomatic LV damage and evaluate cardio-protective treatments [5-9].

Cardio-oncology services become therefore important in proper cardiovascular evaluation of cancer patients before, during and after chemotherapy. As a result of the uniqueness of their situation and the type of care these individuals will need, cardio-oncology is continuously evolving to meet this need. A survey carried out by the Council of Cardio-oncology and Council for cardiology practice of the European Society of Cardiology (ESC) on cardiology care delivered to cancer patients, revealed a gap in knowledge of physicians on cardio-oncology [10]. The ESC 2016 ESC Position Paper on Cancer Treatments and Cardiovascular Toxicity developed under the auspices of the ESC Committee for Practice Guidelines becomes an important guide to the practice of cardio-oncology [11]. The development of cardio-oncology services will bring to light and help strengthen multidisciplinary care of cancer patients especially as it pertains to cardiovascular care amongst cancer patients [1216].

In Nigeria, there is paucity of data on cardio-oncology and this study will be the first documented study assessing the level of knowledge and the activity of cardiology care provided to oncology patients who develop cardiovascular disease in Nigeria and will therefore serve as a template towards the development of cardio-oncology services in Nigeria.

\section{Methodology}

The survey was questionnaire-based and began by assessing the demographic characteristics of participants.

The second part of the questionnaire assessed participants' self-admitted expertise in the management of cardiovascular conditions complicating cancer treatment viz; Systemic Hypertension, Left Ventricular Failure, Atrial Fibrillation and Valvular Heart Disease. Participants were also asked if they had read and implemented the ESC position Paper on cancer treatment and cardiovascular toxicity, about their thoughts concerning the need for cardio-oncology knowledge by cardiologists.
1. Demographic questions:

2. Age

3. Gender

4. Geopolitical Area

5. Place of Work

6. Cadre

Questions used to analyse the professional activities regarding cardiovascular diseases in cancer patients:

1. How many patients with a possible CV complication of cancer treatment did you see in the last 12 months?

2. In your professional environment where are ambulatory cancer patients with cardiovascular health problems reviewed?

3. How do you rate your knowledge and skills about management of patients with Left Ventricular Dysfunction complicating cancer therapy?

4. How do you rate your knowledge and skills about management of patients with Arterial Hypertension complicating cancer therapy treatment?

5. How do you rate your knowledge and skills about management and anticoagulation of patients with Atrial Fibrillation complicating cancer treatment?

6. How do you rate your knowledge and skills about management of patients with Valvular Heart Disease following cancer radiotherapy?

7. In your specific clinical environment do you receive referrals from GPs or other specialists to evaluate a patient with cardiac problems who has received previous cancer therapy?

8. Do you regularly review patients with a known history of cancer treatment for CV diseases?

9. Did you read and apply the suggestions of the 2016 ESC Position Paper on cancer treatments and cardiovascular toxicities?

10. What do you think about the gap of knowledge of the general cardiologists concerning cardio-oncology?

Data were collected via electronic and paper questionnaires distributed to cardiologists across the various geopolitical zones in Nigeria and this was carried between September and October 2019.

\section{DATA ANALYSIS}

Data were analysed descriptively and, where needed, statistically using SPSS version 22.

Data were sorted by gender, age, geopolitical zone within Nigeria, and place of work with the intention of detecting any statistically significant differences between respondents from these groups.

\section{Results}

\subsection{Age and Gender Distribution}

More than two-thirds of respondents $(71.4 \%, \mathrm{n}=55)$ were aged $30-44$ years. There were more male (57.1\%) than female $(42.9 \%)$ respondents. 


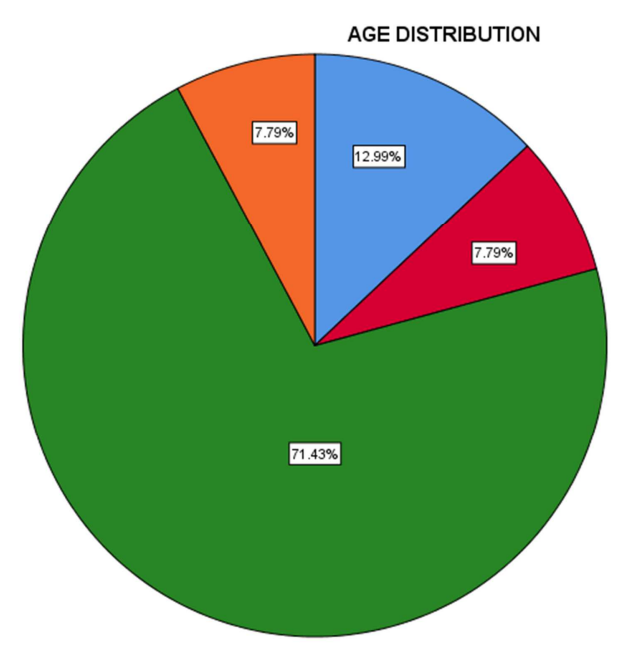

Figure 1. Age distribution of study respondents.

\subsection{Distribution By Geographical Location/Place of Work/Cadre}

Cumulatively, the South-south and South-western regions accounted for over two-thirds of responses $(72.43 \%, n=55)$, with the Northeastern region accounting for the least percentage $(1.30 \%)$ as depicted in figure 2 . Over three-thirds of respondents $(83.12 \%)$ worked at Teaching Hospitals while only $1.3 \%$ each worked at Federal Medical Centres and State's General hospitals. Consultant cardiologists accounted for more than half of respondents $(63.6 \%)$.

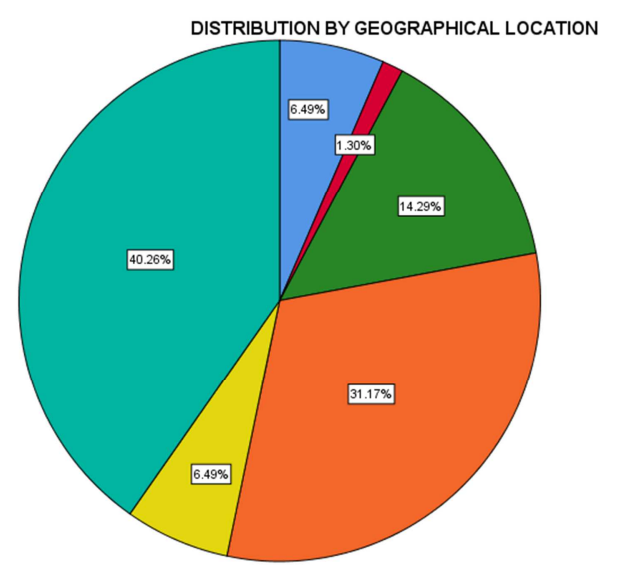

\section{QNORTHWEST
QNORTHEAST
GNORTH CENTRAL
口SOUTHWEST
口SOUTHEAST
GSOUTHSOUTH}

Figure 2. Distribution by geographical location.

\subsection{Number of Patients with Possible Cardiovascular Complication of Cancer Treatment Seen in The Previous 12 Months}

When asked how many patients with possible cardiovascular complication of cancer treatment they had seen in the previous 12 months, $27.3 \%$ of respondents had not seen any, $70.1 \%$ of respondents had seen between 1-20 patients while $2.6 \%$ had seen over 20 patients.

\subsection{Where Ambulatory Cancer Patients with Cardiovascular Health Problems Are Reviewed}

Majority $(89.5 \%)$ of ambulatory cancer patients in need of cardiology care received this service in a general cardiology clinic with only $10.5 \%(\mathrm{n}=8)$ receiving care at a cardiooncology centre.

\subsection{Knowledge of Management of Patients with Common Cardiovascular Conditions}

In response to questions rating their knowledge of management of patients with common cardiovascular conditions (Systemic Hypertension, Atrial Fibrillation, Left Ventricular Dysfunction and Valvular Heart Disease) most participants rated themselves as fair (range 63.3\%-64.5\%).

$27.6 \%$ of respondents rated themselves as having poor knowledge of management of Valvular Heart Disease compared to only $11.7 \%-13.0 \%$ for the other cardiovascular conditions assessed.

\subsection{Referrals from Gps or Other Specialists to Evaluate Patients with Cardiac Problems}

Majority of respondents $(67.1 \%)$ denied receiving referrals from general practitioners or other specialists to evaluate cardiac problems in patients who had received cancer treatment. $25 \%$ of participants said that they rarely received referrals. Cumulatively, $92.1 \%$ of respondents admitted to never or rarely receiving referrals from GPs and other specialists to review cancer patients who developed cardiovascular disease following cancer treatment.

\subsection{Regular Review of Patients with a Known History of Cancer Treatment for Cv Diseases}

Over two-thirds of respondents (69.7\%) admitted to rarely reviewing patients with a known history of cancer treatment for cardiovascular disease. $25 \%$ of respondents said that they did this often.

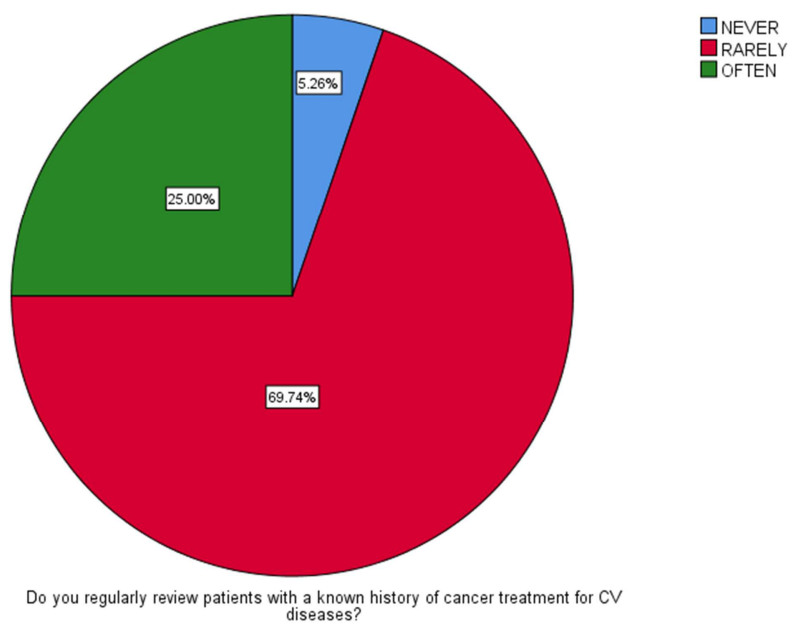

Figure 3. Reviewing patients with cancer treatment for cardiovascular disease.

\subsection{ESC Position Paper}

$80.5 \%$ of participants said that they either did not know about the ESC position paper or knew about it but did not apply its suggestions to their practice. Only $19.5 \%$ of them 
said that they had read it and usually applied it to their practice.

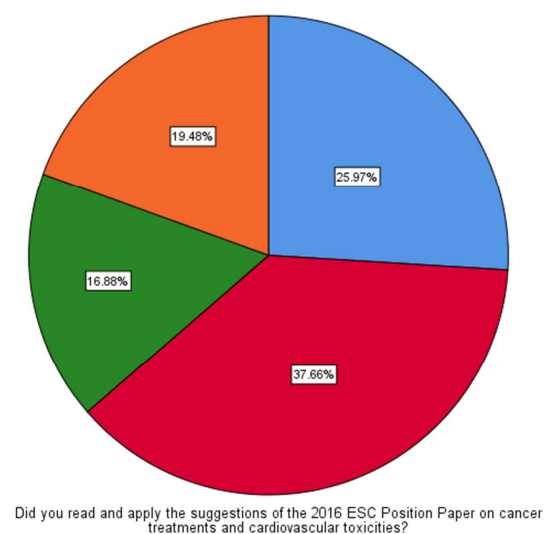

QNo
I don't know this position paper

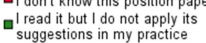

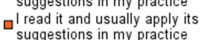

Figure 4. Knowledge and application of 2016 ESC position paper on cardio-oncology.

\subsection{Gap of Knowledge Regarding Cardio-oncology}

93.4\% of respondents admitted that cardio-oncology is a new topic in cardiology, and more information needs to be given about it. $6.6 \%$ of respondents felt that the general cardiologist is already well-trained on it.

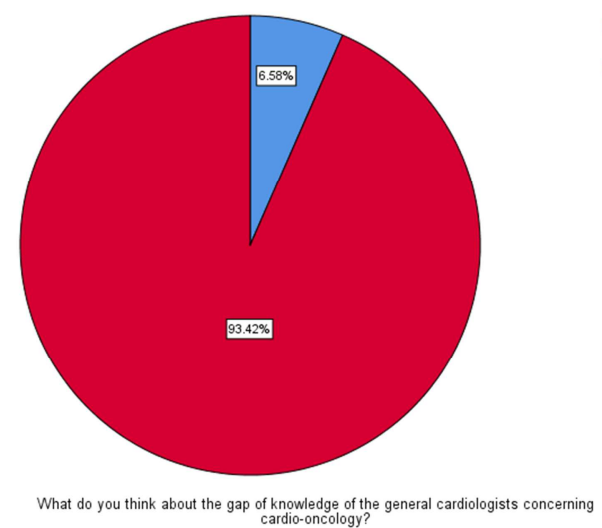

$\square$ It is the same as in other areas
Cardio-Oncology is a new Cardio-Oncology is a new
chapte in cardiology and much
move intormation has to be
given about it

Figure 5. Knowledge gap of general cardiologists concerning cardiooncology.

\subsection{Analysis By Age, Gender, Cadre, Place of Work and Geographic Area}

When analyzing the results by geographical area, it was established that gap of knowledge concerning cardiooncology was high across all the geopolitical regions of the country. $(\mathrm{P}=0.035)$.

Analysisng the survey results by cadre showed that senior registrars were more likely to self-assess as 'poor', their skill in management of Valvular Heart Disease complicating cancer therapy compared with the consultants $(44.4 \%$ vs $2.0 \%, \mathrm{P}=0.017)$.

There were no statistically significant differences between the responses of the males and the females.

There were no statistically significant differences in the responses from participants from different age groups and places of work

\section{Discussion}

This survey, which was modelled after a similar study carried out by the Council for cardio-oncology and Council for cardiology practice of the European Society of Cardiology, is the first survey exploring cardio-oncology knowledge and skills amongst cardiologist in Nigeria. Respondents were cardiologists in various hospitals in Nigeria with over three-thirds of respondents (83\%) working at teaching hospitals unlike the findings in the Europe study where less than half of respondents reported working in an academic university hospital (45\%) [10].

Most respondents in this present study reported seeing 0-5 oncology patients per annum with cardiovascular conditions. This is unlike the ESC study where in response to same question reported that $69 \%$ of respondents had seen between $1-20$ patients while $27 \%(n=160)$ had seen over 20 patients [10]. The complexity of the Nigerian situation and the fact that when patients are sick, the hospital might not be the first port of call cannot be overlooked when assessing this abysmal value. The vast majority of care was provided at general cardiology clinics with only a small percentage being seen at specialized cardio-oncology practices similar to the findings of the ESC study where only $4 \%$ of respondent worked in dedicated cardio-oncology centres in specialist cancer hospitals [10].

The overwhelming majority of cardiologists agreed that cardio-oncology is a relatively new area and that more education needs to be made available in this area. However, most respondents were unaware of the ESC position paper and among those aware, the percentage of respondent who used the paper small. In terms of the position paper, more respondents from outside Europe were unaware of the paper compared to those in Europe. Also, a greater number of respondents in Europe stated that they had read and applied the suggestions in their practice [10].

In addition, most respondents said that they had fair knowledge of management of patients with systemic hypertension, atrial fibrillation and LV dysfunction following cancer treatment similar to the findings in the ESC study [10].

In this present study more than $90 \%$ of the study respondents viewed cardio-oncology as a new chapter in cardiology and there was need for much more information to be given about it similar to the findings of the ESC study [10]. This therefore calls for more effort in propagating and deepening the awareness, importance and practice of cardiooncology globally and Africa in particular.

\section{Conclusion}

Most cancer patients requiring cardiovascular care are seen in the general cardiology clinic of Government owned hospitals in Nigeria. Although the knowledge of cardiologists in the management of cardiovascular complications of cancer patients is adequate, referral from General Practitioners is low. The ESC position paper on cardio-oncology is poorly known and utilized by cardiologist in the care of cancer 
patients with cardiovascular complications with the field of cardio-oncology generally regarded as a new topic in cardiology requiring more information on its dissemination and acceptance.

This survey therefore makes obvious the dearth of knowledge regarding cardio-oncology that is prevalent in Nigeria. It is hoped that this will ignite a change in this aspect. There is therefore an urgent need to for all stakeholders to join force together towards the development of cardio-oncology skills and services in Nigeria.

\section{References}

[1] Ferlay J, Steliarova-Foucher E, Lortet-TieulentJ, Rosso S, Coebergh JW, Comber H, Forman D, Bray F. Cancer incidence and mortality patterns in Europe: estimates for 40 countries in 2012. Eur J Cancer 2013; 49: 1374-1403. Google Scholar, Crossref Pub Med.

[2] Siegel R, DeSantis C, Virgo K, Stein K, Mariotto A, Smith T, Cooper D, Gansler T, Lerro C, Fedewa S, Lin C, Leach C, Cannady RS, Cho H, Scoppa S, Hachey M, Kirch R, Jemal A, Ward E. Cancer treatment and survivorship statistics, 2012. CA Cancer J Clin 2012; 62: 220-241. Google Scholar Crossref Pub Med.

[3] Ewer MS, Ewer SM. Cardiotoxicity of anticancer treatments Nat Rev Cardiol 2015; 12: 620. Google Scholar Crossref Pub Med.

[4] Armstrong GT, Oeffinger KC, Chen Y, Kawashima T, Yasui Y, Leisenring W, Stovall M, Chow EJ, Sklar CA, Mulrooney DA, Mertens AC, Border W, Durand JB, Robison LL, Meacham LR. Modifiable risk factors and major cardiac events among adult survivors of childhood cancer. J Clin Oncol 2013; 31: 3673-3680. Google Scholar Crossref Pub Med.

[5] Subar M, Lin W, Chen W, Pittman DG. Lack of uniformity in cardiac assessment during trastuzumab therapy. Breast J 2011; 17: $383-90$

[6] Civelli M, Cardinale D, Martinoni A, Lamantia G, Colombo N, Colombo Aet al. Early reduction in left ventricular contractile reserve detected by dobutamine stress echo predicts high-dose chemotherapy-induced cardiac toxicity. Int J Cardiol 2006; 111: $120-6$.

[7] Fallah-Rad N, Walker JR, Wassef A, Lytwyn M, Bohonis S, Fang $\mathrm{T}$ et al. The utility of cardiac biomarkers, tissue velocity and strain imaging, and cardiac magnetic resonance imaging in predicting early left ventricular dysfunction in patients with human epidermal growth factor receptor II-positive breast cancer treated with adjuvant trastuzumab therapy. J Am Coll Cardiol 2011; 57: 2263-70.
[8] Sawaya H, Sebag IA, Plana JC, Januzzi JL, Ky B, Tan TC et al. Assessment of echocardiography and biomarkers for the extended prediction of cardiotoxicity in patients trea.

[9] Colombo A, Cardinale D. Using cardiac biomarkers and treating cardiotoxicity in cancer. Future Cardiol 2013; 9: 10518.

[10] Cardiology care delivered to cancer patients; a survey of the Council of Cardio-oncology and of the Council for cardiology practice of the European Society of Cardiology. 2019.

[11] Zamorano JL, Lancelloti P, Munoz DR, Aboyans V, Asteggiano R, Galderisi M, Habib G, Lenihan D, Lip GYH, Lyon AR; 2016 ESC Position Paper on Cancer Treatments and Cardiovascular Toxicity developed under the auspices of the ESC Committee for Practice Guidelines: The Task Force for cancer treatments and cardiovascular toxicity of the European Society of Cardiology; European Heart Journal, Volume 37, Issue 36, 21 September 2016, Pages 2768-2801, https://doi.org/10.1093/eurheartj/ehw211.

[12] Lancellotti P, Suter TM, López-Fernández T, Galderisi M, Lyon AR, Van der Meer P, Cohen Solal A, Zamorano JL, Jerusalem G, Moonen M, Aboyans V, Bax JJ, Asteggiano R. Cardio-Oncology Services: rationale, organization, and implementation: A report from the ESC Cardio-Oncology council. Eur Heart J. 2018 Aug 6. [Epub ahead of print].

[13] European Partnership Action Against Cancer consensus group, Borras JM, Albreht T, Audisio R, Briers E, Casali P, Esperou H, Grube B, Hamoir M, Henning G, Kelly J, Knox S, Nabal M, Pierotti M, Lombardo C, van Harten W, Poston G, Prades J, Sant M, Travado L, Valentini V, van de Velde C, van den Bogaert S, van den Bulcke M, van Hoof E, van den Neucker I, Wilson R. Policy statement on multidisciplinary cancer care. Eur J Cancer. 2014; 50: 475-80.

[14] Parent S, Pituskin E, Paterson DI. The cardio-oncology program: a multidisciplinary approach to the care of cancer patients with cardiovascular disease. Can J Cardiol. 2016; 32: 847-51.

[15] Nancarrow SA, Booth A, Ariss S, Smith T, Enderby P, Roots A. Ten principles of good interdisciplinary team work. Hum Resour Health. 2013; 11: 19.

[16] Plana JC, Galderisi M, Barac A, Ewer MS, Ky B, ScherrerCrosbie M, Ganame J, Sebag IA, Agler DA, Badano LP, Banchs J, Cardinale D, Carver J, Cerqueira M, DeCara JM, Edvardsen T, Flamm SD, Force T, Griffin BP, Jerusalem G, Liu JE, Magalhães A, Marwick T, Sanchez LY, Sicari R, Villarraga HR, Lancellotti P. Expert consensus for multimodality imaging evaluation of adult patients during and after cancer therapy: a report from the American Society of Echocardiography and the European Association of Cardiovascular Imaging. Eur Heart J Cardiovasc Imaging. 2014; 15: 1063-93. 